\title{
P-195
}

\section{Assay Guided Isolation of Glycosides from Micromilum Minutum (Rutacae) with Antioxidant Activities}

\author{
Nur Kartinee Kassim ${ }^{1, *}$, Mawardi Rahmani ${ }^{1}$, Amin Ismail ${ }^{2}$, Mohd Aspollah Sukari ${ }^{1}$ and Aminah \\ Abdullah \\ ${ }^{1}$ Chemistry Department, Faculty of Science, Universiti Putra Malaysia,43400 UPM Serdang, Selangor, Malaysia; \\ ${ }^{2}$ Department of Nutrition and Dietetics, Faculty of Medicine and Health Sciences, Universiti Putra Malaysia,43400 \\ UPM Serdang, Selangor, Malaysia; ${ }^{3}$ School of Chemical Sciences and Food Technology, Faculty of Science and \\ Technology,Universiti Kebangsaan Malaysia; E-mail: kartinee@putra.upm.edu.my
}

Genus Micromelum of the family Rutaceae consists of about 11 species found mostly in tropical and subtropical regions. The plant of this genus have significant medicinal values and traditionally used to treat infected wounds, odynolysis, rheumatism, cough and fevers (Luo et al., 2012). In Malaysia, Micromelum minutum (synonymous with M. Puhescens Blume) is known as "Chemama", "Cherek-cherek" or "Secherek" amongst the local people. Assay guided isolation by using 1,1-diphenyl-2dipicrylhydrazyl (DPPH) radical on methanol extract of Micromilum minutum has led to the isolation and identification of three glycosides (dissacharides (1), alkaloid glycosides (2) and furocoumarin glycosides (3)) which exhibited good antioxidant activities against DPPH, $\beta$-carotene and linoleic oxidation and oxygen radical antioxidant capacity (ORAC). In this presentation we wish to highlight the structural elucidation of the comounds by spectroscopic method and their potential as antioxidant agents against the three different assays.

Keywords: Rutaceae, Micromelum minutum, DPPH, $\beta$-carotene linoleic oxidation, oxygen radical antioxidant capacity (ORAC), glycosides. 